\title{
The Lived Experience of HIV-Infected Patients in the Face of a Positive Diagnosis of the Disease: A Phenomenological Study
}

\section{Shirdel Zandi}

Hamadan University of Medical Sciences

Behzad Imani ( $\sim$ behzadiman@yahoo.com )

Hamadan University of Medical Sciences https://orcid.org/0000-0002-1544-8196

\section{Salman khazaei}

Hamadan University of Medical Sciences

Mohamad Mirzaei

Hamadan University of Medical Sciences

\section{Research}

Keywords: AIDS, HIV, Lived experience, Phenomenological study

Posted Date: July 29th, 2021

DOl: https://doi.org/10.21203/rs.3.rs-715999/v1

License: (a) (i) This work is licensed under a Creative Commons Attribution 4.0 International License. Read Full License 


\section{Abstract}

Background: AIDS as a human crisis may lead to devastating psychological trauma and stress for patients. Therefore, it is necessary to study different aspects of their lives for better support and care. Accordingly, this study aimed to explain the lived experience of HIV-infected patients in the face of a positive diagnosis of the disease.

Methods: This qualitative study is a descriptive phenomenological study. Sampling was done purposefully and participants were selected based on the inclusion and exclusion criteria. Data collection was conducted, using semi-structured interviews. Data analysis was performed using Colaizzi's method.

Results: 12 AIDS patients participated in this study. As a result of data analysis, 5 main themes and 12 sub-themes were identified, which include: emotional shock (loathing, motivation of social isolation), the fear of the consequences (fear of the death, fear of loneliness, fear of disgrace), the feeling of the guilt (feeling of regret, feeling guilty, feeling of conscience-stricken), the discouragement (suicidal ideation, disappointment), and the escape from reality (denial, trying to hide).

Conclusions: The results of this study showed that patients will experience unpleasant phenomenon in the face of the positive diagnosis of the disease and will be subjected to severe psychological pressures that require attention and support of medical and laboratory centers.

\section{Highlights}

- Patients will experience severe psychological stress in the face of a positive diagnosis of HIV.

- Patients who are diagnosed with HIV are prone to make a blunder and dreadful decisions.

- AIDS patients need emotional and informational support when they receive a positive diagnosis.

- As a piece of bad news, presenting the positive diagnosis of HIV required the psychic preparation of the patient

\section{Background}

HIV/AIDS pandemic is one of the most important economic, social, and human health problems in many countries of the world, whose, extent and dimensions are unfortunately ever-increasing (1). In such circumstances, this phenomenon should be considered as a crisis, which seriously affects all aspects of the existence and life of patients and even the health of society (2). Diagnosing and contracting AIDS puts a person in a vague and difficult situation. Patients suffer not only from the physical effects of the disease, but also from the disgraceful consequences of the disease. HIV/AIDS is usually associated with avoidable behaviors that are not socially acceptable, such as unhealthy sexual, relations and drug abuse: So the patients are usually held guilty for their illness (3). On the other hand, the stigma of the disease in society is the cause of rejection and isolation of these patients. In health centers they are again the main obstacles in providing these patients with preventive and diagnosis services as well as healthy sexual 
behaviors (4). Studies show that HIV/AIDS stigma has a completely negative effect on the quality of life of these patients (5). Criminal attitudes towards these patients and rejectionist behaviors by family, community, and medical staff cause blame and discrimination in patients (6). HIV/AIDS stigma is prevalent among diseases, making concealment a major problem in this behavioral disease, The stigma comes in two forms: a negative inner feeling and a negative feeling that other people in the community have towards the patient (7). In a study conducted in the United States to examine the internal stigma of HIV-positive patients, $63 \%$ of the patients felt embarrassed by their condition, and $74 \%$ said it was difficult for them to discuss their illness with others (8). Robert Beckman has defined bad news as "any news that seriously and unpleasantly affects persons' attitudes toward their future". He considers the impact of counseling on moderating a person's feeling of being important (9). Therefore, being infected by HIV / AIDS due to the stigma can be bad news, which will lead to unpleasant emotional reactions (10).

A prerequisite for any successful planning and intervention for people living with AIDS is approaching them and conducting in-depth interviews in order to discover their feelings, attitudes; their views on themselves, their illness, and others; and finally, their motivation to follow up and the participation in interventions (11). Accordingly, the present study aimed to explain the lived experience of HIV-infected patients in the face of a positive diagnosis of the disease, since the better understanding of the phenomena leads to the smoother ways to help and care for these patients.

\section{Methods}

\section{$2-1$. Study setting}

In this study, a qualitative method of descriptive phenomenology was used to discover and interpret the lived experience of HIV-positive patients, when they face a positive diagnosis of the disease. Husserl's four steps of descriptive phenomenology were employed: bracketing, intuiting, analyzing and interpreting (12).

\section{2-2. Participants and sampling}

Sampling was done purposefully and participants were selected based on inclusion criteria. In this purposeful sampling, participants were selected among those patients who had sufficient knowledge about this phenomenon. The sample size was not determined at the beginning of the study, instead it continued until data saturation. Participants were selected from patients who were admitted to the Shohola Behavioral Diseases Counseling Center in Hamadan-Iran. The center has been set up to conduct tests, consultations, medical and dental services, and to distribute medicines among the patients. Additional inclusion criteria for selecting a participant are: having a positive diagnosis experience at the center, having psychological and mental stability, having a favorable clinical condition, willingness to work with the research team, and the possibility of re-access for the second interview if needed. Exclusion 
criteria were unwillingness to participate in the study and inability of verbal communication in Persian language.

\section{2-3. Data Collection}

The interviews began with a non-structured question (tell us about your experience with a positive diagnosis) and continued with semi-structured questions. Each interview lasted 35-70 minutes and was conducted in two sessions if necessary. All interviews were conducted by someone with experience in qualitative research and interviewing. The interview was recorded and then written down with permission of the participant. Data collection was from 1 March to 20 November, 2020.

\section{2-4. Data Analysis}

The descriptive Colaizzi method was used to analyses the collected data (13). This method consists of seven steps: (1) collecting the participants' descriptions, (2) understanding the meanings in depth, (3) extracting important sentences, (4) conceptualizing important themes, (5) categorizing the concepts and topics, (6) constructing comprehensive descriptions of the issues examined, and (7) validating the data following the four criteria set out by Lincoln and Guba.

\section{2-5. Rigor}

Trustworthiness criteria were used to validate the research, due to the fact that importance of data and findings validity in qualitative research (14). This study was based on four criteria of Lincoln and Guba: credibility, transferability, dependability, and conformability (15). For data credibility, prolong engagement and follow-up observations, as well as samplings with maximum variability were used. For dependability of the data, the researchers were divided into two groups and the research was conducted as two separate studies. At the same time, another researcher with the most familiarity and ability in conducting qualitative research, supervised the study as an external observer. Concerning the conformability, the researchers tried not to influence their own opinions in the coding process. Moreover, the codes were readout by the participants as well as two researcher colleagues with the help of an independent researcher and expert familiar with qualitative research. Transferability of data was confirmed by offering a comprehensive description of the subject, participants, data collection, and data analysis.

\section{2-6. Ethical Considerations (Ethical Approval)}

The present study was registered with the ethics code IR.UMSHA.REC.1398.1000 in Hamadan University of Medical Sciences. The purpose of the study was explained and all participants' consents were obtained at first step. All participants were assured that the information obtained would remain confidential and no personal information would be disclosed. Participants were also told that there was 
no need to provide any personal information to the interviewer, including name, surname, phone number and address. To gain more trust, interviews were conducted by a person who was not resident of Hamadan and was not a native of the region, this case was also reported to the participants.

\section{Results}

Twelve AIDS patients participated in this study. The mean age of the participants was 36.41 years. $58.33 \%$ of the participants were male and $41.66 \%$ were married. Of these, 2 were illiterate, 2 had elementary diploma, 6 had high school diploma and 2 had academic education. Six of them were unemployed, 5 were self-employed and 1 was an official employee. These people had been infected by this disease for 6.08 years, in average. (Table 1 )

Table 1

The demographic characteristics of participants

\begin{tabular}{|c|c|c|c|c|c|c|}
\hline Participants & Gender & Age & $\begin{array}{l}\text { Marital } \\
\text { status }\end{array}$ & Education & Job & $\begin{array}{l}\text { Duration of } \\
\text { infection }\end{array}$ \\
\hline P1 & Male & 38 & Single & Diploma & $\begin{array}{l}\text { self- } \\
\text { employed }\end{array}$ & 7 \\
\hline P2 & Female & 41 & Married & Elementary & Unemployed & 6 \\
\hline P3 & Female & 36 & Married & Diploma & Unemployed & 5 \\
\hline P4 & Male & 37 & Single & Academic & Employee & 6 \\
\hline P5 & Female & 42 & Single & Illiterate & Unemployed & 11 \\
\hline P6 & Male & 38 & Married & Diploma & $\begin{array}{l}\text { self- } \\
\text { employed }\end{array}$ & 8 \\
\hline P7 & Male & 32 & Single & Academic & $\begin{array}{l}\text { self- } \\
\text { employed }\end{array}$ & 4 \\
\hline P8 & Male & 39 & Married & Diploma & $\begin{array}{l}\text { self- } \\
\text { employed }\end{array}$ & 7 \\
\hline P9 & Female & 29 & Single & Diploma & Unemployed & 2 \\
\hline P10 & Female & 40 & Single & Elementary & Unemployed & 10 \\
\hline P11 & Male & 31 & Single & Diploma & $\begin{array}{l}\text { self- } \\
\text { employed }\end{array}$ & 4 \\
\hline P12 & Female & 34 & Married & Illiterate & Unemployed & 3 \\
\hline
\end{tabular}

Analysis of the HIV-infected patients' experiences of facing the positive diagnosis of the disease by descriptive phenomenology revealed five main themes: emotional shock, the fear of the consequences, the feeling of the guilt, the discouragement, and the escape from reality. (Table 2) 
Table 2

The themes and sub-thems

\begin{tabular}{|c|c|c|}
\hline \multicolumn{2}{|c|}{ Themes } & Sub-themes \\
\hline \multirow[t]{2}{*}{1} & \multirow[t]{2}{*}{ Emotional shock } & Loathing \\
\hline & & Motivation of social isolation \\
\hline \multirow[t]{3}{*}{2} & \multirow[t]{3}{*}{ The fear of the consequences } & Fear of the death \\
\hline & & Fear of loneliness \\
\hline & & Fear of disgrace \\
\hline \multirow[t]{3}{*}{3} & \multirow[t]{3}{*}{ The feeling of the guilt } & Feeling of regret \\
\hline & & Feeling guilty \\
\hline & & Feeling of conscience-stricken \\
\hline \multirow[t]{2}{*}{4} & \multirow[t]{2}{*}{ The discouragement } & Suicidal ideation \\
\hline & & Disappointment \\
\hline \multirow[t]{2}{*}{5} & \multirow[t]{2}{*}{ The escape from reality } & Denial \\
\hline & & Trying to hide \\
\hline
\end{tabular}

\section{3 - 1. Emotional shock}

Emotional shock is one of the unpleasant events that these patients have experienced after facing a positive diagnosis of the disease. This experience has manifested in loathing and motivation of social isolation.

\section{3-1-1. Loathing}

These patients stated that after facing a positive diagnosis of the disease, they developed a strong inner feeling of hatred towards the source of infection. The patients feel hatred, since they hold the carrier as responsible for their infection. "...After realizing I was affected, I felt very upset with my husband, I did not want to see him again, because it made me miserable, I even decided to divorce ...."(P3)

\section{3-1-2. Motivation of social isolation}

The experiences of these patients showed that after facing the incident, they have suffered an internal failure that has caused them to try to distance from other people. These patients have become isolated, withdrawing from the community and sometimes even from their families. "...After this incident, I decided 
to live alone forever and stay away from all my family members. I made a good excuse and broke up our engagement..." (P7)

\section{3 - 2. Fear of the consequences}

Fear of the consequences is one of the unpleasant experiences that these patients will face, as soon as they receive a positive diagnosis of the disease. Based on experiences, these patients feel fear of loneliness, death, and disgrace as soon as they hear the positive diagnosis.

\section{3-2-1. Fear of the death}

The patients said that as soon as they got the positive test results, they thought that the disease was incurable and would end their lives soon. "... When I found I had AIDS, I was very upset and moved like a dead man because I was really afraid that at any moment this disease might kill me and I would die ..." (P1)

\section{3-2-2. Fear of Loneliness}

The participants stated that one of the most important feelings they experienced as soon as they received a positive diagnosis of the disease was the fear of being alone. They stated that at that moment, the thought of being excluded from society and losing their intimacy with them was very disturbing. "... The thought that I could no longer have a family and had to stay single forever bothered me a lot, it was terrifying to me when I thought that society could no longer accept me as a normal person ... "(P10)

\section{3-2-3. Fear of disgrace}

One of the unpleasant feelings that these patients experienced when faced the positive diagnosis of the disease was the fear of disgrace. They suffer from the perception that the spread of news of the illness hurts the attitudes of those around them and causes them to be discredited. "...It was very annoying for me when I thought I would no longer be seen as a member of my family, I felt I would no longer have a reputation and everyone would think badly of me ..." (P2)

\section{3-3. Feeling of the Guilt}

One of the most important experiences of these patients in facing the positive diagnosis of the disease is feeling guilty. This feeling appears in patients as feeling of regret, guilty and remorse.

\section{3-3-1. Feeling of Regret}


These patients stated that they felt remorse for their lifestyle and actions as soon as they heard the positive diagnosis of the disease, because they thought that if they had lived healthier, they would not have been infected. "...After realizing this disease, I was very sorry for my past, because I really did not have a healthy life. I made a series of mistakes that caused me to get caught. At that moment, I just regretted why I had this disaster ..." (P11)

\section{3-3-2. Feeling Guilty}

The experience of these patients has shown that after receiving a positive diagnosis of the disease, they consider themselves guilty and complain about themselves. These patients condemn their lifestyle and sometimes even consider themselves deserving of the disease and think that it is a ransom that they have paid back. "... after getting the disease, I realized that I was paying the ransom because I was hundred percent guilty, I was the one who caused this situation with a series of bad deeds, and now I have to be punished ..." (P5)

\section{3-3-3. Feeling of conscience-stricken}

One of the most disturbing experiences these patients reported is the pangs of conscience. These patients stated that after receiving a positive diagnosis of the disease, the thought that as a carrier they might have contaminated those around them was very unpleasant and greatly affected their psyche. "... after getting the disease. It was shocked and I was just crazy about the fact that if my wife and children had taken this disease from me, what would I do, I made them hapless ... and this as very annoying for me ..." (P8)

\section{3-4. Discouragement}

Discouragement is an unpleasant experience that patients will experience after receiving a positive HIV test results. Discouragement in these patients appears in the suicidal ideation and disappointment.

\section{3-4-1. Suicidal Ideation}

The patients stated that they were so upset with the positive diagnosis of the illness and they immediately thought they could not live with the fact and the best thing to do was to end their own lives. "... The news was so bad for me that I immediately thought that if the test result was correct and I had AIDS, I would have to kill myself and end this wretch life, oh, I had a lot of problem and the thought of having to wait for a gradual death was horrible to me ..." (P12)

\section{3-4-2. Disappointment}


The experience of these patients shows that a positive diagnosis of the disease for these patients leads to a destructive feeling of disappointment. So that they are completely discouraged from their lives. These patients think that their dreams and goals are vanished and that they have reached the end and everything is over. "... It was a horrible experience, so at that moment I felt my life was over, I had to prepare myself for a gradual death, I was at marriage ages when I thought I could no longer get married, I saw life as meaningless ..." (P7)

\section{3-5. Escape from Reality}

The lived experience of these patients shows that after receiving a positive diagnosis of the disease, they found that this fact was difficult to accept and somehow tried to escape from the reality. This experience has been in the form of denial and trying to hide from others.

\section{3-5-1. Denial}

One of the experiences of these patients in dealing with the positive test result of this disease has been to deny it. In this way, patients believed that the test result was wrong or that the result belonged to someone else. For this reason, the patients referred to other laboratories after receiving the first positive diagnosis of the disease. "...After the lab told me this and found out what the disease really was, I was really shocked and said it was impossible, it was definitely wrong and it is not true ... I could not believe it at all, because I was a professional athlete and this could not happen to me. So I immediately went to a bigger city and there I went to a few laboratories for further tests ..." (P6)

\section{3-5-2.Trying to hide}

These patients stated that after receiving the first positive diagnosis of the disease, they thought that no one should notice their disease and should remain anonymous as much as possible. "... immediately decided that no one in my city should know that I got this disease and the news should not be spread anywhere, so I discard my phone number through which our city laboratory communicated with me and I came here to do a re-examination and go to the doctor, and after all these years, I always come here again for an examination ..." (P4)

\section{Discussion}

In this qualitative study, we attempted to discover lived experience of HIV-infected patients in the face of a positive diagnosis of the disease. Therefore, a descriptive phenomenological method was applied. As a result of this study, based on the experiences of the AIDS patients, the five main themes of emotional shock, fear of the consequences, feelings of guilt, discouragement and, escape from reality were obtained. 
In this study, it was shown that the confrontation of these patients with the positive diagnosis of the disease causes them to experience a severe emotional shock. In this regard, Yangyang Qiu et al. (2014) argued that anxiety and depression are very common among AIDS patients who have recently been diagnosed with the disease (16). The experience of these patients has shown that this emotional shock appears in the form of loathing and the motivation of social isolation. In fact, in these patients, the feeling of the loathing is an emotional response to the primary carrier that has infected them. The study of John B. Pryor et al. (1991) have shown that in an environment where there is an AIDS carrier, other people hate him/her, because they see him/her as a risk factor for their infection (17). The experience of these patients has also shown that receiving a positive diagnosis will motivate social isolation in these patients. Various studies have revealed that one of the consequences of AIDS that these patients will suffer from, is social isolation $(18,19)$.

Another experience of these patients, according to this study is fear of the consequences. This phenomenon appears in these patients as fear of the death, fear of loneliness, and fear of disgrace. Due to the nature of the disease, these patients feel an inner fear of premature death, as soon as they receive a positive diagnosis. In this regard, the study of Audrey K Miller et al. (2012) showed that death anxiety in AIDS patients is a psychological complication (20). These patients have stated that they are very afraid of being alone after receiving a positive diagnosis, which is a natural feeling according to Keith Cherry \& David H. Smith (1993); because these patients will mainly experience some degree of loneliness (21). These patients will also experience a fear of disgrace, which will go back to the nature of the disease and people's insight; but they should be aware that, as Newman Amy states, AIDS is a disease, not a scandal (22).

Another experience of these patients in dealing with the positive diagnosis of the disease is guilt feeling. The patients will experience feelings of regret, the feeling guilty and feeling of the conscience-stricken. The experience of these patients shows that they regret their past. Earlier studies have also revealed that regret for the past is a common phenomenon among the patients living with HIV (23-25). These patients feel guilty while facing the positive diagnosis of the disease and consider themselves the main culprit of the situation. They often play a direct role in their infection, and their past lifestyle for sure (26). Our study also found that these patients feel the conscience-stricken after a positive diagnosis, because they suspect that they may have infected people around them. This disease can be easily transmitted from the carrier to others if the health protocols are not followed (27-29).

Another experience of these patients in dealing with the receiving a positive diagnosis of the disease is discouragement. These patients are disappointed and sometimes decide to suicide. Based on the lived experience of these patients, it was found that receiving a positive diagnosis of the disease, will discourage them from life and patients will be disappointed in many aspects of life. Studies have shown that AIDS, as a crisis, will greatly reduce the patients' life expectancy and that they will continue to live in despair (30). Studies also stated that they considered suicide as a solution to relieve stress when receiving a positive diagnosis. In this regard, various studies have emphasized that among the AIDS patients, loss of self-esteem and severe stress have led to high suicide rates (31-33). 
According to the patients, trying to escape from reality is another phenomenon that they will experience. This phenomenon will occur in patients as denial and trying to hide the disease from others. Based on the lived experience of these patients, it was found that after facing a positive diagnosis, these patients tend to deny that they are infected. In this regard, various studies have shown that these patients in different stages of the disease and their lives try to deny it in different ways (34-36). The patients also stated that at the beginning of the positive diagnosis of the disease, did not want others to know, so they wanted to hide themselves from others in any way possible. In this regard, Emilie Henry et al. (2014) have shown that a high percentage of the patients living with AIDS have tried that others do not notice that they are ill (37).

\section{Conclusion}

The results of this study showed that patients will experience unpleasant experiences in the face of receiving a positive diagnosis of the HIV. Patients' unpleasant experiences at that moment include emotional shock, fear of the consequences, feeling guilty, discouragement and escape from reality. Therefore, medical and laboratory centers must pay attention to the patients' lived experience, and try to support the patients through education, counseling and other support programs to minimize the psychological trauma caused by the disease.

\section{Abbreviations}

AIDS: Acquired immunodeficiency syndrome

HIV: Human immunodeficiency virus

\section{Declarations}

\section{Ethics approval and consent to participate}

This study is the result of a student project that has been registered in Hamadan University of Medical Sciences of Iran with the ethical code IR.UMSHA.REC.1398.1000.

\section{Consent for publication}

Not applicable.

\section{Competing interests}

The authors declare no conflicts of interest. 


\section{Funding}

The study was funded by Vice-chancellor for Research and Technology, Hamadan University of Medical Sciences (No. 9812209934).

\section{Author contributors}

ShZ designed the study, collected the data, and provide the first draft of manuscript. BI designed the study and revised the manuscript. SKh participated in design of the study, the data collection, and revised the manuscript. MM participated in design of the study and revised the manuscript. All authors read and approved the final manuscript.

\section{Acknowledgment}

The authors would like to express their gratitude to the Hamadan Health Network, the Hamadan Shohada Behavioral Diseases Counseling Center, and the participants who helped us in this study.

\section{Author information}

\section{Affiliations}

Shirdel Zandi - M.Sc. Student, Department of Operating Room, Student Research Committee, Hamadan University of Medical Sciences, Hamadan, Iran. Email: shirdel.zandi1994@yahoo.com

Behzad Imani- Assistant professor, Department of Operating Room, School of Paramedicine, Hamadan University of Medical Sciences, Hamadan, Iran. Email: behzadiman@yahoo.com. Corresponding author

Salman khazaei - Research Center for Health Sciences, Hamadan University of Medical Sciences, Hamadan, Iran.salmankhazaei61@gmail.com.

Mohamad Mirzaei -Department of Epidemiology, School of Public Health, Hamadan University of Medical Sciences, Hamadan, Iran. Mirzaei@yahoo.com

Corresponding author: Behzad Imani, Assistant professor, Department of Operating Room, School of Paramedicine, Hamadan University of Medical Sciences, Hamadan, Iran. Email: behzadiman@yahoo.com

\section{Availability of data and materials}

All data relevant to this publication can be obtained by request to the authors. 


\section{References}

1. Farley TM, Samuelson J, Grabowski MK, Ameyan W, Gray RH, Baggaley R. Impact of male circumcision on risk of HIV infection in men in a changing epidemic context-systematic review and meta-analysis. J Int AIDS Soc. 2020;23(6):e25490. doi.org/10.1002/jia2.25490.

2. Steen TW, Drage M, Klouman E. The HIV-pandemic in the third world-worse than anticipated? Tidsskrift for den Norske laegeforening: tidsskrift for praktisk medicin, ny raekke. 2006;126(23):3135-8.

3. Simbayi LC, Kalichman S, Strebel A, Cloete A, Henda N, Mqeketo A. Internalized stigma, discrimination, and depression among men and women living with HIV/AIDS in Cape Town, South Africa. Soc Sci Med. 2007;64(9):1823-31. doi.org/10.1016/j.socscimed.2007.01.006.

4. Chan KY, Stoové MA, Sringernyuang L, Reidpath DD. Stigmatization of AIDS patients: disentangling Thai nursing students' attitudes towards HIV/AIDS, drug use, and commercial sex. AIDS Behav. 2008;12(1):146-57. doi.org/10.1007/s10461-007-9222-y.

5. Beer L, Fagan JL, Valverde E, Bertolli J. Health-related beliefs and decisions about accessing HIV medical care among HIV-infected persons who are not receiving care. AIDS Patient Care STDs. 2009;23(9):785-92. doi.org/10.1089/apc.2009.0032.

6. Tavoosi A, Zaferani A, Enzevaei A, Tajik P, Ahmadinezhad Z. Knowledge and attitude towards HIV/AIDS among Iranian students. BMC Public Health. 2004;4(1):17. doi.org/10.1186/1471-2458-417.

7. Kontomanolis EN, Michalopoulos S, Gkasdaris G, Fasoulakis Z. The social stigma of HIV-AIDS: society's role. Hiv/aids (Auckland. NZ). 2017;9:111. doi:10.2147/HIV.S129992.

8. Lee RS, Kochman A, Sikkema KJ. Internalized stigma among people living with HIV-AIDS. AIDS Behav. 2002;6(4):309-19. doi.org/10.1023/A:1021144511957.

9. Buckman RA. Breaking bad news: the SPIKES strategy. Community oncology. 2005;2(2):138-42.

10. Edwards LV. Perceived social support and HIV/AIDS medication adherence among African American women. Qual Health Res. 2006;16(5):679-91. doi.org/10.1177/1049732305281597.

11. Duru P, Örsal Ö, Karadağ E. Development of an attitude scale for home care. Res Theory Nurs Pract. 2015;29(4):306-24. DOI:10.1891/1541-6577.29.4.306.

12. Husserl E. The phenomenology of internal time-consciousness. Indiana University Press; 2019.

13. Colaizzi PF. Psychological research as the phenomenologist views it. 1978.

14. Creswell JW. Educational research: Planning, conducting, and evaluating quantitative. Prentice Hall Upper Saddle River, NJ; 2002.

15. Lincoln Y, \&Guba EG. Naturalistic Inquiry. New bury Park.: Sage Publications; 1985.

16. Qiu Y, Luo D, Cheng R, Xiao Y, Chen X, Huang Z, et al. Emotional problems and related factors in patients with HIV/AIDS. Zhong nan da xue xue bao Yi xue ban = Journal of Central South University Medical sciences. 2014;39(8):835. DOI: 10.3969/j.issn.1672-7347.2014.08.014. 
17. Pryor JB, Reeder GD, McManus JA. Fear and loathing in the workplace: Reactions to AIDS-infected co-workers. Pers Soc Psychol Bull. 1991;17(2):133-9. doi.org/10.1177/014616729101700203.

18. Holtz CS, Sowell R, Velasquez G. Oaxacan women with HIV/AIDS: Resiliency in the face of poverty, stigma, and social isolation. Women Health. 2012;52(6):517-35. doi.org/10.1080/03630242.2012.690839.

19. Emlet CA. An examination of the social networks and social isolation in older and younger adults living with HIV/AIDS. Health Soc Work. 2006;31(4):299-308. doi.org/10.1093/hsw/31.4.299.

20. Miller AK, Lee BL, Henderson CE. Death anxiety in persons with HIV/AIDS: A systematic review and meta-analysis. Death Stud. 2012;36(7):640-63. doi:10.1080/07481187.2011.604467.

21. Cherry K, Smith DH. Sometimes I cry: The experience of loneliness for men with AIDS. Health Commun. 1993;5(3):181-208. doi.org/10.1207/s15327027hc0503_3.

22. Newman A. AIDS: A Disease Not a Disgrace: Kalamazoo, Mich. Kalamazoo College.; 1992.

23. Epstude K, Jonas KJ. Regret and counterfactual thinking in the face of inevitability: The case of HIVpositive men. Social Psychological Personality Science. 2015;6(2):157-63. doi.org/10.1177/1948550614546048.

24. Dibb B. Assessing, Stigma. Disclosure Regret and Posttraumatic Growth in People Living with HIV. AIDS Behav. 2018;22(12):3916-23. doi.org/10.1007/s10461-018-2230-2.

25. Parrish G. Remorse. Despondence, and the Acceptance of an Early Death: An Allegory of the AIDS Epidemic. Amherst College; 1999.

26. Redfield RR, Burke DS. HIV Infection. Sci Am. 1988;259(4):90-9.

27. Kennedy DP, Cowgill BO, Bogart LM, Corona R, Ryan GW, Murphy DA, et al. Parents' disclosure of their HIV infection to their children in the context of the family. AIDS Behav. 2010;14(5):1095-105. doi.org/10.1023/A:1024252926930.

28. Sherrod HM. A psycho-educational group to enhance coping skills for children with parents who are infected with HIV/AIDS: a thesis submitted to the department of social work in partial fulfillment of the requirements for the degree of master of social work: Southern Connecticut State University; 1999.

29. Abebe W, Teferra S. Disclosure of diagnosis by parents and caregivers to children infected with HIV: prevalence associated factors and perceived barriers in Addis Ababa, Ethiopia. AIDS care. 2012;24(9):1097-102. doi.org/10.1080/09540121.2012.656565.

30. Pokrovsky V, Nladnaia N, Pokrovskaya A. HIV/AIDS is reducing the number of Russians and their life expectancy. Демографическое обозрение. 2017;4(5).

31. Shim E-J, Lee SH, Kim NJ, Kim ES, Bang JH, Sohn BK, et al. Suicide risk in persons with HIV/AIDS in South Korea: a partial test of the interpersonal theory of suicide. Int J Behav Med. 2019;26(1):38-49. doi.org/10.1007/s12529-018-9749-5.

32. Kelbert E, Pinheiro L, Souza L, Pinheiro C, Pinheiro K, Motta J, et al. Suicide risk in people living with AIDS/HIV: the effect of childhood trauma is mediated by mental disorders and social vulnerability. 
AIDS care. 2020;32(4):512-7. doi.org/10.1080/09540121.2019.1695732.

33. Glass RM. AIDS, Suicide. JAMA. 1988;259(9):1369-70. 10.1001/jama.1988.03720090059037.

34. Kamen C, Taniguchi S, Student A, Kienitz E, Giles K, Khan C, et al. The impact of denial on healthrelated quality of life in patients with HIV. Qual Life Res. 2012;21(8):1327-36. doi.org/10.1007/s11136-011-0045-y.

35. Ironson G, Friedman A, Klimas N, Antoni M, Fletcher MA, LaPerriere A, et al. Distress, denial, and low adherence to behavioral interventions predict faster disease progression in gay men infected with human immunodeficiency virus. International Journal of Behavioral Medicine. 1994;1(1):90-105. doi.org/10.1207/s15327558ijbm0101_6.

36. Carrico AW, Antoni MH, Durán RE, Ironson G, Penedo F, Fletcher MA, et al. Reductions in depressed mood and denial coping during cognitive behavioral stress management with HIV-positive gay men treated with HAART. Ann Behav Med. 2006;31(2):155-64. doi.org/10.1207/s15324796abm3102_7.

37. Henry E, Bernier A, Lazar F, Matamba G, Loukid M, Bonifaz C, et al. "Was it a mistake to tell others that you are infected with HIV?": Factors associated with regret following HIV disclosure among people living with HIV in five countries (Mali, Morocco, Democratic Republic of the Congo, Ecuador and Romania). Results from a community-based research. AIDS Behav. 2015;19(2):311-21. doi.org/10.1007/s10461-014-0976-8. 